\title{
Türkiye'nin Orta Fırat Bölümü'nün Bulanık Mantık Yaklaşımı ve Aylık Aydeniz Metodu Kullanılarak Kuraklık Analizi
}

\author{
Emre Topçu ${ }^{*}$ \\ 1* Kafkas Üniversitesi, Mühendislik-Mimarlık Fakültesi, İnşaat Mühendisliği Bölümü, Kars, Türkiye, (ORCID: 0000-0003-0728-7035), emretopcu01@ gmail.com
} (İlk Geliş Tarihi 26 Ocak 2021 ve Kabul Tarihi 28 Mart 2021)

(DOI: $10.31590 /$ ejosat.868545)

ATIF/REFERENCE: Topçu, E. (2021). Türkiye'nin Orta Fırat Bölümü’nün Bulanık Mantık Yaklaşımı ve Aylık Aydeniz Metodu Kullanılarak Kuraklık Analizi. Avrupa Bilim ve Teknoloji Dergisi, (23), 296-303.

\section{$\ddot{O} \mathbf{z}$}

Bu çalışmada, Türkiye'nin en kurak bölümlerinden biri olan Orta Fırat Bölümü’nde Bulanık Mantık Yaklaşımı ve Aylık Aydeniz Metodu kullanılarak bir kuraklık analizi yapılması amaçlanmıştır. Çalışmada; Gaziantep, Adıyaman ve Şanlıurfa olmak üzere 3 adet meteoroloji gözlem istasyonunun aylık ortalama yağış, aylık ortalama sıcaklık, aylık ortalama nispi nem ve aylık toplam güneşlenme süresi parametreleri kullanılarak kuraklık analizi gerçekleştirilmiştir. Her istasyonun tecrübe ettiği 7 farklı kuraklık sınıfının görülme yüzdeleri bulunmuştur. Sonuçlara göre bölgenin tamamının çoğunlukla çöl iklimine sahip olduğu gözlemlenmiştir. Oransal olarak çöl ikliminin en fazla yaşandığı istasyon Şanlıurfa olarak bulunmuştur. Aylık Aydeniz Metodu ile elde edilen ve gözlenmiş değerler olarak kabul edilen kuraklık katsayısı değerleri, Bulanık Mantık Yaklaşımı'nda 85 adet kural tabanı oluşturularak tahmin edilmeye çalışılmıştır. Tahmin yüzdesinin en yüksek olduğu il \%87.5'lik doğru tahmin etme oranıyla Şanlıurfa istasyonudur. Ortalama doğru tahmin etme oranı \%83'ün üzerindedir. Böylece, bölgede kuraklık analizinde kullanılan yöntemlerin karar vericilere su kaynakları planlanmasında yol göstermesi beklenmektedir.

\section{Drought Analyses of the Middle Firat Part of Turkey by Using Fuzzy Logic Approach and Monthly Aydeniz Method}

\begin{abstract}
In this study, it is aimed to conduct a drought analyses in Middle Firat Part, which is one of the most drought parts of Turkey using Fuzzy Logic Approach and Monthly Aydeniz Method. Monthly average precipitation, monthly average temperature, monthly average humidity and monthly total sunshine duration parameters of 3 meteorological stations namely Gaziantep, Adiyaman and Şanlıurfa were exploited for drought analyses. The percentages of 7 different drought classes experienced by each station were found. According to the results, it was observed that the entire region has a mostly desert climate. The station where the desert climate is experienced the most in proportion is Şanlıurfa. The drought coefficient values obtained with the Monthly Aydeniz Method and accepted as observed values were tried to be estimated by creating 85 rule bases in Fuzzy Logic Approach. The province with the highest estimation percentage is Şanlıurfa station with $87.5 \%$ correct prediction rate. Average correct estimation rate is over $83 \%$. Thus, the methods used in drought analysis in the region are expected to guide decision-makers in planning water resources.
\end{abstract}

Keywords: Drought, Aydeniz Method, Fuzyy Logic, Climate.

\footnotetext{
*Sorumlu Yazar: emretopcu01@gmail.com
} 


\section{Giriş}

İklim, bir bölgede, olabildiğince uzun bir dönemde saptanan hava durumunun sınır ve ortalama değerlerinin tümüne denir. $\mathrm{Bu}$ nedenle yıllara göre koşullardaki değişmeler hava değişikliğidir; iklim değişikliği değildir. Fakat bir bölgenin iklimi de binlerce yıl veya daha uzun dönemlerde değişiklik gösterebilmektedir (Aydeniz, 1985). Küresel 1sınma iklim değişikliğini tetiklemektedir. Küresel ısınmanın zararlarını kontrol etmenin ya da en azından azaltmanın ilk adımı, her bölgedeki etkisini tanımlamakla olur (Abbasnia ve diğ., 2016).

İklim öğelerini sıcaklık, nem, nemlilik, bulutluluk, yağış, hava basınc1, hava hareketleri ve buharlaşma olarak gruplandırabiliriz. Bu öğelerden bir veya birden fazlasının normalden sapması, görüldüğü bölgede, kısa ya da uzun vadede hava değişikliğine neden olmaktadır. Hava değişikliğinin belki de en ürkütücü olumsuz sonuçları kuraklık ve çoraklıktır. Çünkü bütün canlıların temel ihtiyacı olan ve vücutlarını meydana getiren su, eksikliğinde strese ve telafisi olmayan hasarlara yol açar. Kuraklık, bozulan iklim hadisesinin devam etme süresine göre genellikle geçicidir. Ancak uzun periyotta devam ederse geri dönüşü olmayan çevresel tahribata yol açar. Bu olaya ise çoraklık denir ve olumsuz etkisi kalıcıdır. Kuraklık, oluşma sırasına göre meteorolojik, tarımsal, hidrolojik ve sosyoekonomik kuraklık olarak kategorize edilebilir. Dönemsel yağış eksikliğinde ilk olarak meteorolojik kuraklık kendisini hissettirir. Ardından yeterli nemi alamayan bitkiler için tarımsal kuraklık başlar. Sürecin devam etmesi neticesinde, artan su talepleri nedeniyle, su kaynaklarında azalma meydana gelir ve hidrolojik kuraklıktan bahsedilir. Nihayetinde bölgede kıtlık, suya hükmetme savaşları başlar. $\mathrm{Bu}$ da sosyoekonomik kuraklığın göstergesidir (Wilhite \& Glantz, 1987).

Sulak alanlar dünya ekosisteminin dengesini ve devamlılığını sağlayan yeryüzünün en önemli ve kıymetli parçalarından biridir. Büyük bir sistemin parçaları olan bu alanlar, yer aldıkları sahanın iklimi, su kaynakları ve jeomorfolojik özelikleri gibi çevresel faktörlere karşı çok duyarlı olmakla birlikte, özellikle kuraklık sorunu ile karşı karşıyadır (Çakaroz ve diğ., 2020). Kuraklığın oluşma zamanını tahmin etmek zor olsa da, alınacak bazı çevresel ve hidrolojik önlemlerle, kuraklık gerçekleştiğinde negatif etkileri kısa süre de olsa hissedilmeyebilir. Örneğin baraj, gölet, akarsu gibi su kaynaklarını optimum düzeyde yönetmek suyun varlığını sürekli kılar. Hafif şiddetli kuraklıklarda herhangi bir yan etki görülmez.

İnsanların yaşamsal ya da sanayide üretim amaçlı harcadığ su miktarı, beklenmedik bir kuraklığa neden olabilir. Çünkü su kaynaklarının planlanarak yönetildiği bölgelerde mevcut su varlığının haddinden fazla kullanılması, su kaynaklarının dengesini bozabilir. Su israfi hangi amaçla olursa olsun kesinlikle yapılmamalıdır. Özellikle kalabalık ve sanayileşmiş şehirlerde depolama suyunun önemi daha fazladır. İsraf edilen su kuraklığın daha erken başlamasına sebebiyet verebilir. İsraf, ürün veya hizmetlere değer katmayan faaliyetlerin tümüdür (Sevgili \& Antmen, 2019). Özellikle kalabalık ve sanayileşmiş şehirlerde sanayinin su kullanımı en yüksek seviyededir. Zaman ilerledikçe, teknoloji geliştikçe; müşteri ihtiyaç ve beklentileri artmakta dolayısı ile yöneticilerin de istekleri değişmektedir (Akçimen \& Antmen, 2019). Bu da daha fazla suyun kullanımına yol açabilmektedir.
Yapılacak kuraklık analizleri ile geçmişe dönük kurak dönemlerin belirlenmesi, bir bölgede kuraklığın ne kadar sık yaşandığını ve devam etme süresini açığa çıkarabilir. Ĕ̆er çok s1k tekrarlanan kuraklık hadiseleri, uzun soluklu belirli periyotlarda gerçekleşiyorlarsa, ilerleyen zamanlar için kuraklık tahminin de bile bulunulabilir. İklim öğelerini gözlemleyerek, çeşitli iklim parametrelerini inceleyerek kuraklık yargısına ulaşılabilir. Literatürde matematiksel olarak formülize edilmiş çok sayıda kuraklık hesaplama yöntemi bulunmaktadır. En popüler olarak kullanılanlara örnek verecek olursak; De Martonne Metodu (De Martonne, 1942), Palmer Kuraklık Şiddet İndisi (Palmer, 1965), Ondalıklar Kuraklık İndeksi (Gibbs \& Maher, 1967), Aydeniz Metodu (Aydeniz, 1973), Erinç Yöntemi (Erinç, 1984), Standartlaştırılmış Yağış İndeksi (Mckee ve diğ., 1993), Bütünleşik Kuraklık İndeksi (Keyantash \& Dracup, 2004), Keşif Kuraklık İndeksi (Tsakiris \& Vangelis, 2005), Akım Kuraklık İndeksi (Nalbantis, 2008) gibi yöntemler örnek olarak verilebilir.

Bu çalışmada, Türkiye'nin en kurak bölgeleri arasında yer alan Orta Fırat Bölümü'nde iklimsel olarak kuraklık analizi yapılmıştır. Orta Firat Bölümü, Dicle Böümü'nden sonra Türkiye'de yaz sıcaklığı ve buharlaşmanın en fazla olduğu bölgedir. Orta Firat Bölümü'nün denize uzaklığı ve sıcak rüzgârlara açık bir konumda bulunması kurak olmasında en büyük etkendir. $\mathrm{Bu}$ bölgede sanayice nispeten gelişmiş; Gaziantep, Adıyaman ve Şanlıurfa olmak üzere insanların yoğun olarak yaşadığı iller bulunmaktadır. Dolayısıyla; sanayi, tarım ve yaşamsal olarak suyun varlığının büyük önem taşıdığı söylenebilir. Küresel iklim değişikliğinin fazlaca tartışıldığı bu dönemde, çalışma bölgesi yaşanılmaz bir çöl olma durumuyla karşı karşıya kalmıştır. Sosyoekonomik kuraklığın meydana gelmesi durumunda, bölge, canlı popülasyonu bakımından olumsuz etkilenecektir. Bu nedenle çalışma alanı olarak bu bölge seçilmiştir.

Çalışmada ilk olarak Aylık Aydeniz Metodu kullanılmış ve meteoroloji istasyonlarının iklimsel olarak kuraklık türleri belirlenmiştir. Akabinde ise Bulanık Mantık Yaklaşımı ile eldeki parametreler kullanılarak geçmişe dönük kuraklıklar tahmin edilmeye çalışılmıştır. Her iki yöntem sonuçları karşılaştırılarak yöntemlerin kuraklığ tespit etme ve birbirilerini doğrulama kapasiteleri incelenmiştir. Çalışmadaki üç istasyonun da iklimleri belirlenmiş ve hangi zamanlarda kuraklık ya da tam tersi ıslaklığın görüldüğü belirlenmiştir.

\section{Materyal ve Metot}

\subsection{Materyal}

Materyal olarak Orta Frrat Bölümü'nde yer alan Gaziantep, Adıyaman ve Şanlıurfa meteoroloji istasyonlarından elde edilen aylık ortalama yağış $(\mathrm{mm})$, aylık ortalama sıcaklık $\left({ }^{\circ} \mathrm{C}\right)$, aylık ortalama nem (\%) ve aylık toplam güneşlenme süreleri (saat), analizlerde girdi parametresi olarak kullanılmıştır. Parametrelerin değerleri Meteoroloji Genel Müdürlüğü’nden elde edilmiştir. Çalışma alanının konumu Şekil 1'de gösterilmektedir. 


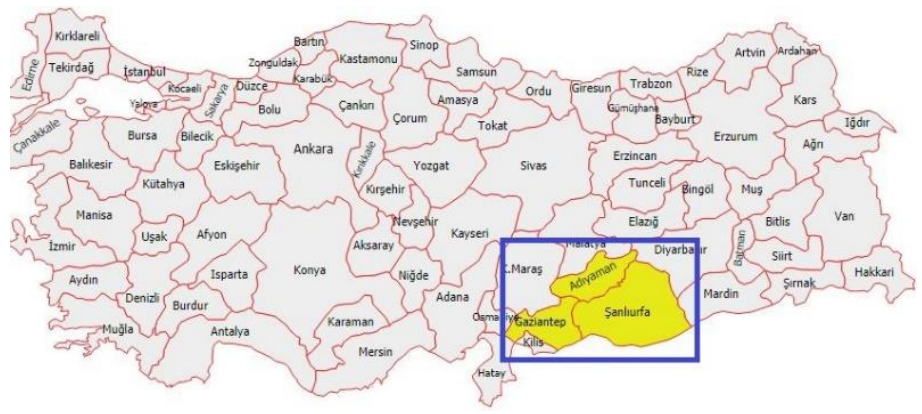

Şekil 1. Çalı̧̧ma alaninin Türkiye'deki konumu

Verisi elde edilen meteoroloji istasyonlarının coğrafi bilgileri ise Tablo 1'de verilmektedir.

Tablo 1. Meteoroloji istasyonlarının coğrafi bilgileri

\begin{tabular}{ccccc}
\hline No & Adı & Kot $(\mathbf{m})$ & $\mathbf{X}$ (Enlem) K & $\mathbf{Y}$ (Boylam) D \\
\hline 17261 & Gaziantep & 854 & 37.0585 & 37.351 \\
\hline 17265 & Adıyaman & 672 & 37.7553 & 38.2775 \\
\hline 17270 & Şanlıurfa & 550 & 37.1608 & 38.7863 \\
\hline
\end{tabular}

17261 No'lu Gaziantep ve 17265 No'lu Adryaman meteoroloji istasyonları 1968-2013 (552 ay), 17270 No'lu Şanlıurfa istasyonu ise 1960-2013 (648 ay) yılları arasında parametre serisine sahiptirler.

\subsection{Metot}

\subsubsection{Aylık Aydeniz Metodu}

Aydeniz, 1973 yılında, ülkemizin iklim koşullarını göz önüne alarak kuraklık hadisesine etkisi olan faktörleri (güneşlenme süresi, oransal nem, kuraklık periyodu) de içeren bir katsayı geliştirmiştir. Nemlilik katsayısı olarak adlandırılan bu katsayı $\left(N_{k s}\right)$, aylık değerlerin hesabında Eşitlik 1 kullanilarak elde edilmektedir.

$N_{k s}=\frac{y x N x 12}{\left(S x G_{S}\right)+15}$

Eşitlik 1'de,

$N_{k s}:$ aylık nemlilik katsayısını

$y: \mathrm{cm}$ cinsinden aylık ortalama yağışı

$S$ : aylık ortalama sicaklığ $\left({ }^{\circ} \mathrm{C}\right)$

$N$ : \% olarak oransal nemi

$G_{s}: \%$ olarak güneşlenme süresi'ni ifade etmektedir.

\% olarak güneşlenme süresi, gerçek güneşlenme süresinin her enlem derecesine göre değişen teorik güneşlenme süresine oranı ile elde edilir. Bu değerin elde edilişi (Bölük, 2016) çalışmasında ayrıntılı olarak yer almaktadır. Kuraklık katsayısı $K_{k s}$ ise Eşitlik 2 yardımıyla elde edilir.

$K_{k s}=\frac{1}{N_{k s}}$

Bu şekilde bulunan Nemlilik Katsayıları $\left(N_{k s}\right)$ ve Kuraklık Katsayıları $\left(K_{k s}\right)$ 'nin özellikleri Tablo 2'de verilmiştir. Aylık Aydeniz Metodu'nda kuraklık katsayısı değerlerine göre, kurak dönemler; Çöl, Çok kurak, Kurak, Kurakça, Nemlice, Nemli ve Islak olmak üzere 7 sınıfta kategorilendirilmiştir.

Tablo 2. Nemlilik-Kuraklık katsayılarının iklim özellikleri (Aydeniz, 1985)

\begin{tabular}{ccc}
\hline $\boldsymbol{N}_{\boldsymbol{k} \boldsymbol{s}}$ & $\boldsymbol{K}_{\boldsymbol{k} \boldsymbol{s}}$ & İklim \\
\hline$<0.40$ & $>2.50$ & Çöl \\
\hline $0.40-0.67$ & $1.50-2.50$ & Çok kurak \\
\hline $0.67-1.00$ & $1.00-1.50$ & Kurak \\
\hline $1.00-1.33$ & $0.75-1.00$ & Kurakça \\
\hline $1.33-2.00$ & $0.50-0.75$ & Nemlice \\
\hline $2.00-4.00$ & $0.25-0.50$ & Nemli \\
\hline$>4.00$ & $<0.25$ & Islak \\
\hline
\end{tabular}

\subsubsection{Bulanık Mantık Yaklaşımı}

Bulanık Mantık Yaklaşımı bir yaklaşık akıl yürütme metotudur ve söz konusu durumları modellerken belirsizliklerle başa çıkmak için faydalıdır. Bu yaklaşım ilk olarak (Zadeh, 1965) tarafindan ortaya konulmuştur ve yaptığ çalışmada insan zihninin çoğunlukla bulanık olduğunu ve kesin olmadığını belirtmiştir. Araştırmalar bulanık mantık yaklaşımı ile elde edilen sonuç performansının bilinen yöntemlerle bulunanlara göre daha iyi olduğunu ortaya çıkarmıştır (Elmas, 2003). Zadeh tarafından ortaya konulan bulanık model (Antmen \& Miç, 2018) ve (Miç \& Antmen, 2019) çalışmalarında farklı bir boyutuyla ele alınmıştır.

Klasik kümeler olarak bilinen kesin kümeler ait olduğu evrensel kümenin her bir elemanına 1 ya da 0 değerini atamaktadır.
Bir nesne 1 değerini alırsa kümenin elemanıdır, 0 değerini alırsa kümenin elemanı değildir. Bulanık mantıkta belirsizlik durumları, bu durumu temsil eden küme elemanlarına üyelik fonksiyonlarının verilmesi ile tanımlanır. En büyük önem derecesine sahip olan öğelere 1 değeri atanırsa, diğerleri 0 ile 1 arasında değişim gösterir. Bu şekilde 0 ile 1 arasındaki değişimin her bir öğe için değerine üyelik derecesi ve bunun bir alt küme içindeki değişimine de üyelik fonksiyonu denir. (Demir \& Gençoğlu, 2004). Bulanık Mantık bulanık denetleyiciden oluşur. Şekil 2'de basit bir bulanık denetleyici mekanizması verilmektedir. 


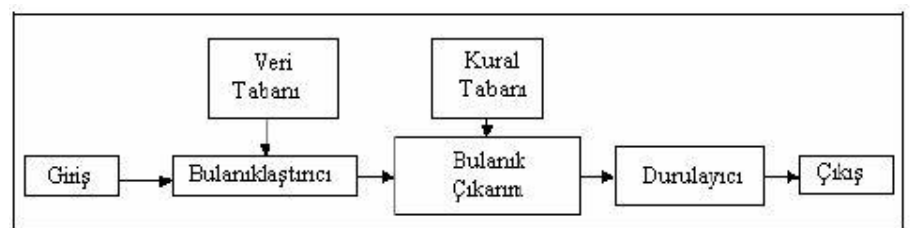

Şekil 2. Bulanıklaştırma-Durulaştırma birimli bulanık sistem (Aksoy, 2003)

Literatürde bulanık kural tabanında modelleme çeşitleri bulunmaktadır. Bu çalışmada Mamdani Bulanık Mantık yöntemi (Mamdani \& Assilian, 1975) kullanılmıştır. Bu yöntem, sözel bulanık model "eğer- o halde" kuralları şeklinde (yarı-) nitel bilginin kullanılabilmesi için olanak sağlamaktadır. Kuralların oluşturulmasından sonra elde edilen bulanık çıktılar ağırlık merkezi, ortalama merkezi, en büyüklerin ortası, açıortay yöntemleri gibi çeşitli metotlar kullanılarak durulanmış çıktı haline gelir (Çeribaşı \& Doğan, 2016).

$\mathrm{Bu}$ çalışmada kuraklık tespiti amacıyla toplamda 85 adet kural tabanı oluşturulmuştur. Kural tabanında yağış, sıcaklık, nispi nem ve güneşlenme süreleri için VL (very low), L (low), M (moderate), H (high), VH (very high) şeklinde kurallar atanmıştır. Tüm analizler Matlab uygulamasında gerçekleştirilmiştir. Örnek kural tabanı Tablo 3 'te yer almaktadır.

Tablo 3. Çalışmada oluşturulan örnek kural tabanı

\begin{tabular}{ccccc}
\hline Yağış & Sicaklık & Nispi Nem & G. Süresi & Durum \\
\hline VL & M & VL & H & Çöl \\
\hline VL & H & M & M & Çok Kurak \\
\hline VL & L & M & M & Kurak \\
\hline VL & VL & M & M & Nemlice \\
\hline M & H & M & H & Nemli \\
\hline H & H & H & H & Islak \\
\hline VH & M & VH & VL & \\
\hline
\end{tabular}

$\mathrm{Bu}$ çalışmada yapılan analizlerin performansını değerlendirmek için Kök Ortalama Kare Hata Değeri (RMSE) hesap edilmiştir, RMSE (Root Mean Square Error) değerleri Eşitlik 3 yardımıyla bulunmuştur. $\mathrm{Bu}$ denklemde $\mathrm{n}$ gözlem sayısıdir.

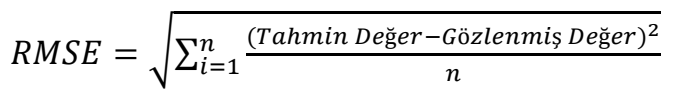

\section{Araştırma Sonuçları ve Tartışma}

Ülkemizde ve çalışma bölgesinde en kurak ay Ağustos ayıdır. Yapılan analizler neticesinde çalışmada yer alan 3 istasyonda da en kurak ayda, aylık ortalama sıcaklıklarda artış tespit edilmiştir. Ortalama yağışta ise son yıllarda, daha önceki yıllara benzemeyen pik yapan yă̆ışlar kaydedilmiştir. Bunun nedeninin; küresel 1sınmanın iklimi bozması, uzun süre yağış oluşmaması, oluştuğunda da yağışın çok şiddetli ve kısa süreli olmasından kaynaklanabileceği düşünülmektedir. 17261 ve 17270 No'lu istasyonlarda aylık ortalama nem değerlerinde ise azalış eğilimi vardır. Bunun nedeni güneyden gelen sıcak ve kuru hava dalgasının sıklığının artması olabilir. 17265 No'lu istasyonda ise birbirini takip eden kurak ve sslak dönemler göze çarpmaktadır. İstasyonlarda aylık toplam güneşlenme süresi ise azalış eğilimindedir ancak son yıllarda nispeten artış görülmüştür.

Gaziantep (17261), Adıyaman (17265) ve Şanlıurfa (17270) meteoroloji istasyonlarının aylık ortalama yağış, aylık ortalama sicaklık, aylık ortalama nispi nem ve aylık ortalama toplam güneşlenme süreleri Tablo 4'de gösterilmiştir. Bu değerlere göre aylık ortalama yağış ve aylık ortalama nispi nemin en yüksek olduğu yer 17261 No'lu istasyon, aylık ortalama sıcaklık ve aylık ortalama toplam güneşlenme süresinin en yüksek olduğu yer 17270 No'lu istasyondur. Yağış, sıcaklık, nispi nem ve güneşlenme sürelerinin, eldeki seriler kullanılarak elde edilen minimum ve maksimum değerleri Tablo 5 'te verilmektedir. $\mathrm{Bu}$ tabloya göre aylık ortalama yağış en fazla 17265 No'lu istasyonda, en az ise 17261 No'lu istasyondadır. En yüksek aylık ortalama sıcaklık 17270 No'lu istasyonda görülmüştür. Aylık ortalama nispi nemin en yüksek olduğu istasyon 17261 No'lu istasyondur. Aylık toplam güneşlenme süresi ise 17270 No'lu istasyonda en fazladır.

Tablo 4. Istasyonların iklim parametrelerinin aylık ortalama değerleri

\begin{tabular}{ccccc}
\hline No & $\begin{array}{c}\text { Yağış } \\
(\mathbf{m m})\end{array}$ & $\begin{array}{c}\text { Sicaklık } \\
\left({ }^{\circ} \mathbf{C}\right)\end{array}$ & $\begin{array}{c}\text { Nispi } \\
\text { Nem (\%) }\end{array}$ & $\begin{array}{c}\text { G. Süresi } \\
(\text { saat })\end{array}$ \\
\hline 17261 & 47.1 & 15.1 & 61.0 & 218.4 \\
\hline 17265 & 58.3 & 17.2 & 49.2 & 241.4 \\
\hline 17270 & 38.2 & 18.4 & 50.7 & 246.3 \\
\hline
\end{tabular}

Tablo 5. İstasyonların iklim parametrelerinin min. ve maks. değerleri

\begin{tabular}{ccc|cc|cc|cc}
\cline { 2 - 9 } & \multicolumn{2}{c|}{ Yağış } & \multicolumn{2}{c|}{ Sıcaklık } & \multicolumn{2}{c|}{ Nispi Nem } & \multicolumn{2}{c}{ G. süresi } \\
\cline { 2 - 9 } & Min. & Maks. & Min. & Maks. & Min. & Maks. & Min. & Maks. \\
\hline 17261 & 0 & 259.4 & -3.2 & 31.2 & 28.1 & 90.2 & 47.7 & 419.5 \\
\hline 17265 & 0 & 367.1 & -0.2 & 33.5 & 13.7 & 81 & 53.4 & 420.8 \\
\hline 17270 & 0 & 324.9 & 1.2 & 34.8 & 17.2 & 85.8 & 58.5 & 437.4 \\
\hline
\end{tabular}


Aylık Aydeniz Metodu ile bulunan nemlilik $\left(N_{k s}\right)$ ve kuraklık $\left(K_{k s}\right)$ katsayıları zaman serileri haline getirilmiştir. Elde edilen sonuçlara göre 17261 No'lu istasyonda özellikle haziran, temmuz, ağustos aylarında çöl iklimi yaşandığı tespit edilmiştir. Hatta ekim, kasım ve nisan aylarında bile çöl iklimi görülebilmektedir. En yüksek $N_{k s}$ değerleri 1968 ve 1969 yılları Ocak ayında ve 2001 yılı Aralık ayında görülmüştür. Toplam 552 ay içerisinde 213 ay çöl, 30 ay çok kurak, 23 ay kurak, 21 ay kurakça, 55 ay nemlice, 95 ay nemli ve 115 ay ise 1slak olarak tespit edilmiştir. $\mathrm{Bu}$ değerlerin toplam ay sayısı içerisindeki yüzde oranları elde edilmiştir. 17261 No'lu istasyon için kuraklık sınıflarına göre yüzdeler Şekil 3 'te verilmektedir.

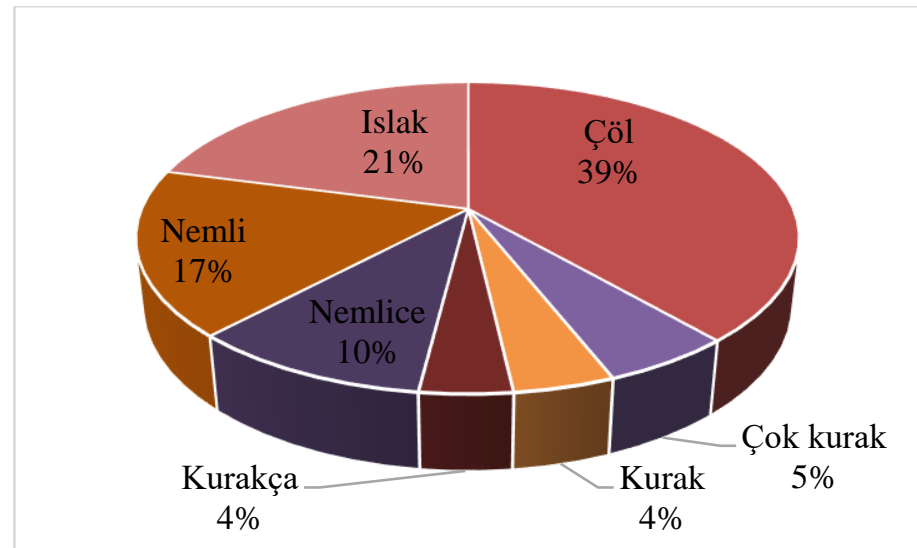

Şekil 3. 17261 No'lu istasyon için kuraklık sınıfı yüzdeleri

Şekil 4'de ise aylar boyunca $N_{k s}$ değerlerinin değişimi gösterilmektedir.

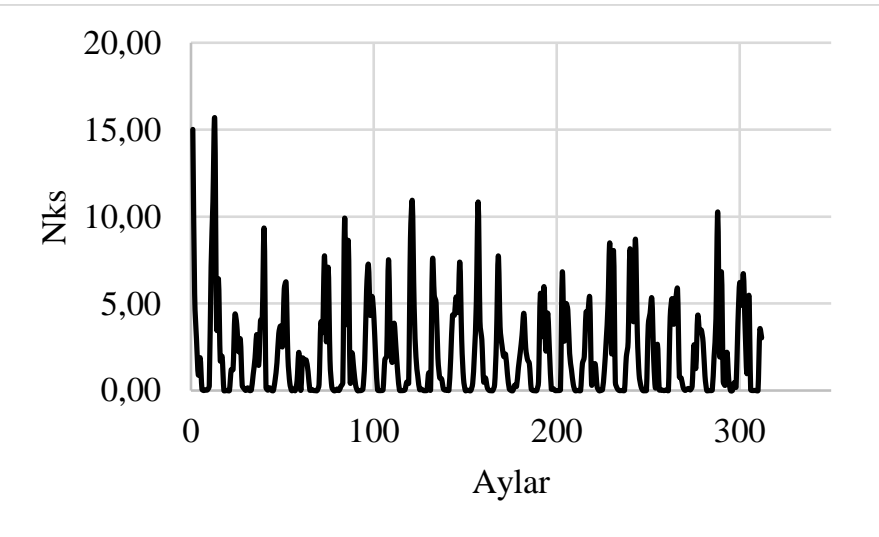

\section{Şekil 4. 17261 No'lu istasyon için $N_{k s}$ değerlerinin aylık olarak değişimi}

17265 No'lu istasyonda haziran, temmuz, ağustos ve eylül aylarında çöl iklimi görülmektedir. Kasım, mart, nisan ve mayıs aylarında bile çöl ikliminin yaşanabildiği tespit edilmiştir. En yüksek $N_{k s}$ değerleri 1969 yılı Ocak ayı, 2001 yılı Aralık ayı ve 2012 y1lı Aralık ayında görülmüştür. Bu istasyonun sahip olduğu 552 aylık zaman serisinde 230 ay çöl, 26 ay çok kurak, 25 ay kurak, 20 ay kurakça, 42 ay nemlice, 91 ay nemli ve 118 ayın ise 1slak olduğu ortaya çıkmıştır. 17265 No'lu istasyon için kuraklık sınıflarına göre yüzdeler Şekil 5'de verilmektedir. Şekil 6'da ise aylar boyunca $N_{k s}$ değerlerinin değişimi gösterilmektedir.

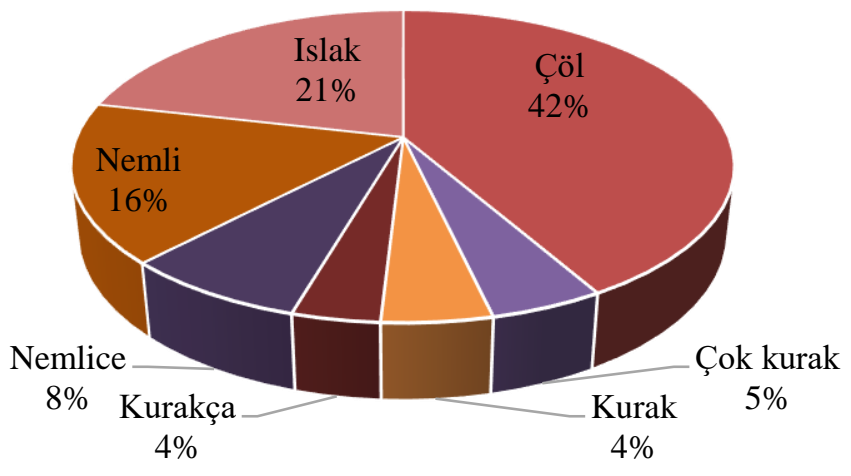

Şekil 5. 17265 No'lu istasyon için kuraklık sınıfi yüzdeleri

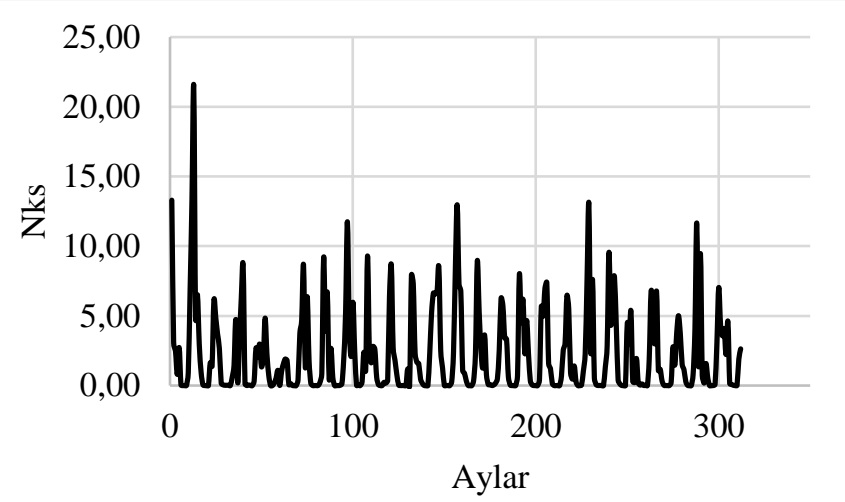

Şekil 6. 17265 No'lu istasyon için $N_{k s}$ değerlerinin aylık olarak değişimi

17270 No'lu istasyonda da benzer durumlar yaşanmıştır. Ancak en büyük $N_{k s} 1960$ ve 1969 yılları Ocak ayında ve 1996 yılı Mart ayında görülmüştür. Bu istasyonda sahip olduğu 648 aylık zaman serisi boyunca 306 ay çöl, 31 ay çok kurak, 36 ay kurak, 39 ay kurakça, 60 ay nemlice, 92 ay nemli ve 84 ay 1slak olarak tespit edilmiştir. Çöl ikliminin en fazla ve islaklığın en az görüldüğü istasyon bu istasyon olarak gözlemlenmiştir. 17270 No'lu istasyon için kuraklık sınıflarına göre yüzdeler Şekil 7'de verilmektedir. Şekil 8 'de ise aylar boyunca $N_{k s}$ değerlerinin değişimi gösterilmektedir.

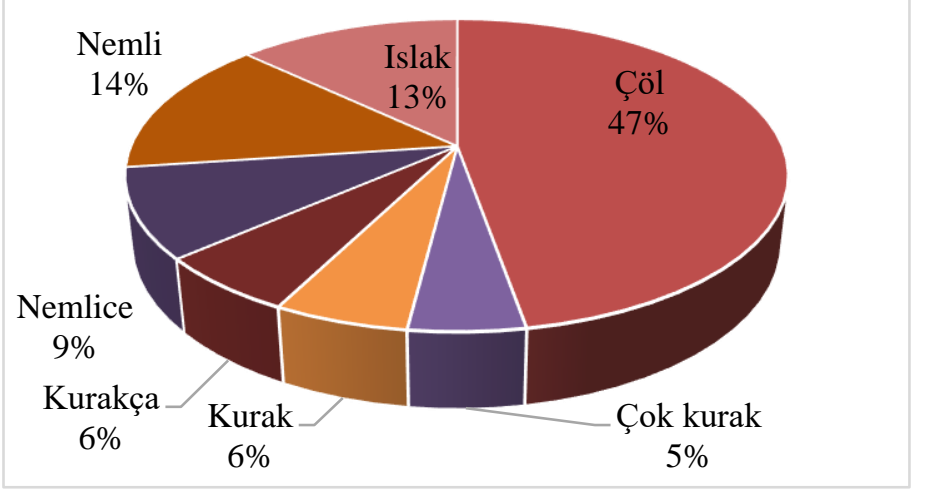

Şekil 7. 17270 No'lu istasyon için kuraklık sınıfı yüzdeleri 


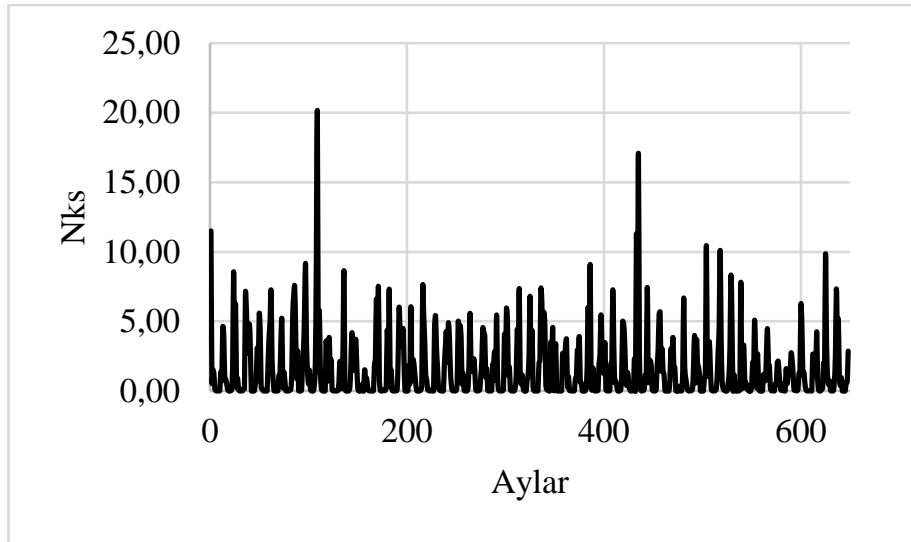

Şekil 8. 17270 No'lu istasyon için $N_{k s}$ değerlerinin aylık olarak değ
İstasyonların pasta grafikleri incelendiğinde çoğunlukla çöl ikliminin hâkim olduğu göze çarpmaktadır.

Bulanık mantık yönteminde kullanılan 85 kural tabanı ile elde edilen kuraklık sonuçları irdelenmiştir. $\mathrm{Bu}$ incelemede, Aylık Aydeniz Metodu ile elde edilenler "Durum", Bulanık Mantık yaklaşımı ile oluşturulan kuraklık ve nemlilik sayıları "Tahmin" olarak isimlendirilmiştir. Aylık Aydeniz Metodu ile elde edilen aylık kuraklık ve nemlilik durumlarının, Bulanık Mantık Yaklaşımı ile elde edilen tahminler ile karşılaştırıldığında yüzde olarak birbirini tutturma oranı elde edilmiştir. 17261 No'lu istasyona ait Durum ve Tahmin değerleri ve iklim sınıfına denk gelen gözlenmiş ve tahmin edilmiş ay sayısı Tablo 6'da verilmiştir. Bu sonuçlara göre yapılan 552 tahminden 461 iklim tipi doğru tespit edilmiştir. Bu sayı oldukça yüksek bir değer olan \% 83.51'e denk gelmektedir.

Tablo 6. 17261 No'lu istasyonun kuraklık sinıflarına göre tahmin değerleri

\begin{tabular}{|c|c|c|c|c|c|c|c|}
\hline \multicolumn{8}{|c|}{ GAZİNTEP (17261) } \\
\hline Durum $={ }^{\text {Tahmin }}$ & Çöl & Çok Kurak & Kurak & Kurakça & Nemlice & Nemli & Islak \\
\hline Çöl & 202 & 3 & 8 & 0 & 0 & 0 & 0 \\
\hline Çok Kurak & 7 & 23 & 0 & 0 & 0 & 0 & 0 \\
\hline Kurak & 4 & 0 & 17 & 2 & 0 & 0 & 0 \\
\hline Kurakça & 2 & 0 & 0 & 19 & 0 & 0 & 0 \\
\hline Nemlice & 0 & 0 & 0 & 0 & 24 & 31 & 0 \\
\hline Nemli & 0 & 0 & 0 & 0 & 1 & 67 & 27 \\
\hline Islak & 0 & 0 & 0 & 0 & 0 & 6 & 109 \\
\hline
\end{tabular}

Tablo 7'de 17265 No'lu istasyon için kuraklık sınıflarına denk gelen tahmin değerleri gösterilmektedir. 552 aydan 463 tanesi doğru tahmin edilmiştir. Bu da, \%83.88 başarı ile doğru tahmin edildiği anlamına gelmektedir.

Tablo 7. 17265 No'lu istasyonun kuraklık sinıflarına göre tahmin değerleri

\begin{tabular}{|c|c|c|c|c|c|c|c|}
\hline \multicolumn{8}{|c|}{ ADIYAMAN (17265) } \\
\hline Durum $={ }^{\text {Tahmin }}$ & Çöl & Çok Kurak & Kurak & Kurakça & Nemlice & Nemli & Islak \\
\hline Çöl & 229 & 1 & 0 & 0 & 0 & 0 & 0 \\
\hline Çok Kurak & 8 & 16 & 2 & 0 & 0 & 0 & 0 \\
\hline Kurak & 0 & 6 & 18 & 1 & 0 & 0 & 0 \\
\hline Kurakça & 0 & 0 & 1 & 12 & 7 & 0 & 0 \\
\hline Nemlice & 0 & 0 & 0 & 4 & 24 & 14 & 0 \\
\hline Nemli & 0 & 0 & 0 & 0 & 3 & 64 & 24 \\
\hline Islak & 0 & 0 & 0 & 0 & 0 & 18 & 100 \\
\hline
\end{tabular}


Tablo 8'de ise 17270 No'lu istasyon için durum ve tahmin değerleri gösterilmektedir. 648 ayın 567'si doğru tahmin edilmiştir. Doğru tahmin yüzdesi $\% 87.5^{\prime}$ tir. Tablolardan anlaşlacağı üzere en yüksek doğru tahmin yüzdesine 17270 No'lu istasyon sahiptir. 3 istasyonun da RMSE değerleri Tablo 9'da verilmektedir.

Tablo 8. 17270 No'lu istasyonun kuraklık sinıflarına göre tahmin değerleri

\begin{tabular}{|c|c|c|c|c|c|c|c|}
\hline \multicolumn{8}{|c|}{ ŞANLIURFA (17270) } \\
\hline Durum $=$ Tahmin & Çöl & Çok Kurak & Kurak & Kurakça & Nemlice & Nemli & Islak \\
\hline Çöl & 289 & 6 & 11 & 0 & 0 & 0 & 0 \\
\hline Çok Kurak & 7 & 24 & 0 & 0 & 0 & 0 & 0 \\
\hline Kurak & 0 & 0 & 32 & 4 & 0 & 0 & 0 \\
\hline Kurakça & 0 & 0 & 1 & 37 & 1 & 0 & 0 \\
\hline Nemlice & 0 & 0 & 0 & 0 & 47 & 11 & 2 \\
\hline Nemli & 0 & 0 & 0 & 0 & 1 & 63 & 28 \\
\hline Islak & 0 & 0 & 0 & 0 & 0 & 9 & 75 \\
\hline
\end{tabular}

Tablo 9. İstasyonların RMSE ve doğru tahmin yüzdeleri

17261

$$
R M S E=2.0476
$$

Doğru Tahmin $=461$

Toplam Tahmin $=552$

Doğru Tahmin $=\% 83.51$

RMSE $=2.5737$

17265

Doğru Tahmin $=463$

Toplam Tahmin $=552$

Doğru Tahmin $=\% 83.88$

RMSE $=1.6379$

17270

Doğru Tahmin $=567$

Toplam Tahmin $=648$

Doğru Tahmin $=\% 87.5$

\section{Sonuç}

Kuraklık yaşamsal faaliyetleri suya dayalı bütün varlıklar için endişe verici bir durumdur. İster iklim koşulları gereği ister küresel ısınmanın bozduğu iklim parametreleri sebebiyle oluşsun, doğru tahmin ve analiz, kuraklı̆ğı etkilerinin en aza indirilmesinde çok önemli bir husustur. $\mathrm{Bu}$ çalışmada Türkiye'nin Orta Furat Bölümü'nde bulunan üç meteoroloji istasyonunda kuraklık analizi yapılmıştır. Bu bölgenin analiz için seçilmesinde en büyük etken, ikliminin hali hazırda çöl iklimi olarak yaşanmasıdır. Gerek insan kaynaklı gerekse doğal hadiselerle meydana gelen küresel 1sınma sebebiyle bölgede kuraklığın daha da şiddetleneceği düşüncesi, çalışmada, analizi bu coğrafi bölümde yapmaya yönlendirmiştir.

Çalışmada Aylık Aydeniz Metodu ve Bulanık Mantık Yaklaşımı tercih edilmiştir. Aydeniz metodu, Meteoroloji Genel Müdürlüğü tarafindan da kuraklığın tespiti amaciyla güncel olarak kullanılmaktadır. Bulanık Mantık Yaklaşımı'nda da Mamdani çıkarım yöntemi kullanılmıştır. Elde edilen sonuçlara göre çalışma bölgesi bütün olarak daha çok çöl ikliminin tecrübe edildiği bir yerdir. Aydeniz Metodu ve 85 kural tabanı oluşturularak kullanılan Bulanık Mantık yöntemleri karşılaştırıldığında birbirini doğrulama konusunda en yüksek oranın 17270 No'lu Şanlıurfa istasyonunda olduğu ortaya çıkmıştır. Bölgede kuraklık çoğunlukla yaz aylarında görülmektedir, ancak diğer mevsimlerde de görülebilmektedir.

Geçmişe yönelik yapılan bu kuraklık analizi çalışmasında bölgenin çok kurak bir bölge olduğu hatta çöl iklimine sahip olduğu bir kez daha ortaya konulmuştur. Bölgenin iklimsel doğası nedeniyle az olan su kaynaklarının varlığının devam edebilmesinin; nüfus planlaması, tarımsal reform, insanların eğitilmesi, su kaynaklarının bilinçli kullanılması ve yönetilmesi gibi konuların gündeme getirilmesine bağlı olduğu düşünülmektedir. Ayrıca çalışmada kullanılan yöntemlerin bölge için uygun olduğu kanısına varılmıştır. Bu çalışmada kullanılan bulanık mantık yöntemi için sınırlı sayıda kural tabanı oluşturulabilmiştir. Ancak, Orta Fırat Bölümü ya da herhangi bir bölge için yapılması planlanan gelecekteki kuraklık çalışmalarında daha kapsamlı bulanık mantık kural tabanları oluşturulabilir. İleri yıllardaki kentsel veya tarımsal projeksiyonlar için su kaynaklarının kullanılması konusunda bu çalışmanın planlamacılara fikir vermesi umulmaktadır. 


\section{Kaynakça}

Abbasnia, M., Tavousi, T., Khosravi, M., Toros, H. (2016). Investigation of interactive effects between temperature trend and urban climate during the last decades: a case study of Isfahan-Iran. European Journal of Science and Technology, Vol 4, No 7, pp 74-81.

Akçimen, C. \& Antmen, F. (2019). Kısıtlar Teorisinde Kapasite Kısıtı ve Bir Üretim İşletmesinde Uygulaması. Avrupa Bilim ve Teknoloji Dergisi, (15), 618-626.

Aksoy, S. (2003). İnşaat Mühendisliğinde Çok Amaçlı Değerlendirme ve Karar Vermede Fuzzy Yaklaşımı 179 s., Yüksek Lisans Tezi, İstanbul Üniversitesi, Fen Bilimleri Enstitüsü, İstanbul.

Antmen, F. Z., \& Miç, P., (2018). Çocuk Yoğun Bakım Ünitesinde Çok Kriterli Karar Verme ile Mekanik Ventilatör Seçimi ve Bir Uygulama Örneği. Çukurova Üniversitesi Mühendislik Mimarlık Fakültesi Dergisi, 33(4), ss. 17-30.

Aydeniz, A. (1973). Tarımda verimliliğin sağlanmasında önemli etken olan su ve sulama durumumuz. Verimlilik Dergisi, 3/1: 177-199.

Aydeniz, A. (1985). Toprak Amenajman1-I. Ankara Üniversitesi Ziraat Fakültesi Yayınları: 928, Ders Kitabı: 263.

Çakaroz, D., Özelkan, E. \& Karaman, M. (2020). Sulak Alanlarda Uzaktan Algilama ile Belirlenen Zamansal Değişime Kuraklığın Etkisinin İncelenmesi: Umurbey Deltası (Çanakkale) Örneği. Avrupa Bilim ve Teknoloji Dergisi, (20), 898-916.

Çeribaşı, G., \& Doğan, E. (2016). Aşağı Sakarya Nehrindeki Askı Maddesi Miktarının Esnek Yöntemler ile Tahmini. Karaelmas Fen ve Mühendislik Dergisi, 6(2):351-358.

De Martonne, E. (1942). Nouvelle carte mondiale de l'indice d'aridité. Annales de Géographie 51: 242-250.

Demir, F., Gençoğlu, M. \& Güler, K. (2004). Çelik Tel Takviyeli Betonların Gerilme-Şekil Değiştirme Davranışı için Bir Bulanık Mantık Yaklaşımı. Türkiye İnşaat Mühendisliği 17. Teknik Kongre ve Sergisi, 15-16-17 Nisan 2004, İstanbul.

Elmas, Ç. (2003). Bulanık Mantık Denetleyiciler. Seçkin Yayınevi, ISBN 975347613 2, Ankara.

Erinç, S. (1984). Klimatoloji ve Metotları, İ.T.Ü. Deniz Bilimleri ve Coğrafya Enstitüsü, İstanbul.

Gibbs, J. W., \& Maher, V. J. (1967). Rainfall Deciles as Drought Indicators. Bureau of Meteorology. Australia, 48, 33s.

Keyantash, A. J., \& Dracup, A. J. (2004). An aggregate drought index: Assessing drought severity based on fluctuations in the hydrologic cycle and surface water storage. Water Resources Research, Vol 40, W09304.

Mamdani, E. H. \& Assilian, S. (1975). An experiment in linguistic synthesis with a fuzzy logic controller, Int. Journal of Man-Machine Studies, 7(1), 1-13.

Mckee, T. B., Doesken, N. J. \& Kleist, J. (1993). The Relationship of Droght Frequency and Duration to Time
Scales. Reprints, 8th Conference on Applied Climatalogy, Anaheim, CA, USA, 179-184 p.

Miç, P. \& Antmen, Z. F. (2019). A Healthcare Facility Location Selection Problem with Fuzzy TOPSIS Method for a Regional Hospital. Avrupa Bilim ve Teknoloji Dergisi, (16), 750-757.

Nalbantis, I. (2008). Evaluation of a Hydrological Drought Index. European Water Publications, 23/24:67-77.

Palmer, W. C. (1965). Meteorological Drought, U.S.weather Bureau, Research Paper No.45.

Sevgili, A. \& Antmen, Z. F. (2019). Yalın Üretim Tekniklerinden Değer Akış Haritalandırmanın Bir Metal İşleme Fabrikasında Süreç İyileştirme Amacıyla Uygulanması. Avrupa Bilim ve Teknoloji Dergisi, (16), 219-228.

Tsakiris, G., \& Vangelis, H. (2005). Establishing a Drought Index Incorporating Evapotranpiration. European Water Publications, 9/10:3-11.

Wilhite, D. A., \& Glantz, M. H. (1987). Understanding the Drought Phenomenon: The Role of Definitions. In: Planning for Drought: Toward a Reduction of Societal Vulnerability. Westview Press, Boulder, Colorado, pp 11-30.

Zadeh, L. A. (1965). Fuzzy Sets, Information and Control. Academic Pres, New York, Vol. 8, pp 338-353. 